\title{
STUDY OF THE COMPRESSIVE RESPONSE OF MASONRY USING NON-CONVENTIONAL JOINT MATERIALS
}

\author{
Ernest Bernat-Maso*, Christian Escrig and Lluis Gil \\ Department of Strength of Materials and Engineering Structures \\ Universitat Politècnica de Catalunya \\ Terrassa, Spain \\ Email: ernest.bernat@upc.edu \\ Email: christian.escrig@upc.edu \\ Email:1luis.gil@upc.edu \\ * Corresponding author: Colom 11, TR45 D137, 08222 Terrassa, Spain
}

\begin{abstract}
The compressive response of masonry is influenced by geometric, material and execution variables. In addition, the nature of bricks and mortar typically introduce uncertainty to the experimental results. In order to reduce this uncertainty, an experimental campaign has been carried out to analyse the influence of the properties of the joints. Four non-conventional masonry typologies including resin, EPS and rubber joints have been considered for this purpose. Sixty compressive tests and fifty deformability tests on 5 stacked bricks prisms were performed. Obtained data is compared with data from the literature. A comparison with the current European standard is also carried out. The obtained results point out that the modulus of linear deformation of the joint is the most influent variable on the compressive response of masonry. Finally, it seems that current formulation (Eurocode 6) tends to overestimate the modulus of linear deformation of masonry.
\end{abstract}

Keywords: Compressive strength, Masonry, Modulus of linear deformation, Mortar, Epoxy Resin, Eurocode, Joint thickness.

\section{INTRODUCTION}

Masonry has been used as a construction material for thousands of years. However, the characterisation of its mechanical properties is still a challenge because of the nature of this hand-made composite material.

In the 1970s, researches like the one carried out by Watstein and Allen (Watstein and Allen, 1970) pointed out the problem of the scattering of the experimental results obtained by testing masonry elements. Two decades later, the work by Kirstchig and Anstötz (Kirtschig and Anstötz, 1991) on characterising masonry walls or the research by Molins (Molins, 1996) about historical masonry still dealt with the distinctive scattering of this material at determining basic properties like the compressive strength $\left(f_{c}\right)$ or the Young's modulus $(E)$. A few years ago, the influence of the manual production of masonry on its properties and the corresponding scattering was still discussed by Sandoval et al. (Sandoval et al., 2011), as a part of a wider research dealing with the buckling phenomena of masonry walls.

In this line, for example, different ratios of the Young's modulus out of the compressive strength are proposed by the current codes. Hence, Eurocode-6 (European Committee for Standardization, 1997) suggests using $E / f_{c}=1000$, while ACI-530 (Masonry Standards Joint Committee, 2005) recommends $E / f_{c}=700$. The Mexican code (Gobierno del Distrito Federal, 2004) even proposes two different values depending on the case: $E / f_{c}=350$ for short-term actions and $E / f_{c}=600$ for long-term solicitations. 
Moreover, the experimental evidences extended the range for the ratio $E / f_{c}$ including lower possible values than the ones included in the standards. In this line, Maurenbrecher (Maurenbrecher, 1985) obtained $E / f_{c}$ ratios between 600 and 800, Brencich (Brencich et al., 2008; Brencich and Felice, 2009; Brencich and Gambarotta, 2005) set this range between 120 and 300 and Bernat et al. (Bernat et al., 2013) presented evidences which reduced the $E / f_{c}$ ratio down to $40-70$.

The disagreement between published results and the significant scattering of the corresponding evidences has encouraged researchers to perform additional tests to characterise basic parameters of masonry. In this line one of the first works was the study carried out by Maurenbrecher (Maurenbrecher, 1983, 1980) who investigated the influence of several variables (geometry, curing time, contact area in the joints, type of joints and handwork) on the compressive response of masonry. Later on, investigations were more oriented to find the constitutive law of masonry in compression: Knutsson (Knutsson, 1991) suggested that the Young's modulus depended on the stress. In this same line Oliveira (Oliveira, 2000) observed the hysteretic response of masonry and concluded that moulded mortar for producing standardised samples did not represent the mortar in the joints because of the influence of the bricks in real structures. Thus, the environmental and interface conditions influence the properties of the components so the response of the compound material, masonry, may be affected as well. The work by Roberts et al. (Roberts et al., 2006) about the impact of moisture in the mechanical properties of masonry is an evidence of this fact.

The influence of the mechanical properties and the geometry of the component layers has been deeply analysed by Brencich et al. (Brencich et al., 2008, 2002), who performed experimental researches, analytical studies and numerical simulations of the compressive response of masonry. These researches used a previously presented formulation, by Francis et al. (Francis et al., 1971), to calculate the Young's modulus of masonry from the Young's modulus of the components, their Poisson's coefficient and the thickness of the brick and mortar layers. This formulation is based on the mixture theory and uses the elasticity principles. In this same line, Brencich et al. (Brencich et al., 2008) proposed a formulation to calculate the compressive strength of unbounded masonry. This was based on the assumptions of limit analysis and related the compressive and tensile strength of mortar and bricks with the compressive strength of masonry, including the influence of the component's thickness.

Thus, the literature review has bring the idea that there is no agreement about the characterisation of the compressive response of masonry elements. In addition, previous experimental researches have not been able to completely justify the scattering of their results and it is observed that the requirements of current numerical models for simulating masonry demand a better understanding of the compressive response of this composite material. In this line, the influence of the joints is always pointed as a key parameter. Because of this, it is intended to enhance the knowledge about the compressive response of masonry by testing non-conventional masonry elements compound by current bricks and joints made of epoxy resins, rubber or eps foam, which were bonded or dry piled depending of the case. Using well-characterised non-conventional materials for the joints allows focusing the analysis of the masonry response on the interface area and the brick behaviour. The data and analyse presented in this paper are intended to be the basis to calibrate new or existing numerical models counting with a wider extend of properties of the joint materials and better knowledge about their interaction. 
Finally, the experimentally obtained results are compared with literature data. All this information is compared with the formulation proposed in Eurocode 6 and other references. This analysis makes it possible to identify in which range of the considered variables the current Eurocode 6 brings the best fitting results.

\section{MATERIALS AND METHODS}

\subsection{MATERIALS}

Commercial 270x125x50 $\mathrm{mm}^{3}$ solid fired clay bricks were used for all tests. These were produced by the company Ceramica Farreny S.A. and were classified as category I according with their compressive strength, which was evaluated by the producer following the standard EN 771-1 (Committee AEN/CTN 136, 2011). Nevertheless, the compressive strength was determined in laboratory facilities following the standard EN 772-1 (Committee AEN/CTN 41, 2002) and the flexural strength was determined performing three-points bending tests with a free span of $200 \mathrm{~mm}$ and a loading rate of $100 \mathrm{~N} / \mathrm{s}$. The main properties of the used ceramic pieces are summarised in Table 1.

Two cement mortars were considered in the present research. The first one (Mortar I) was a commercial Portland cement mortar for general brickwork applications distributed under the name Valsec $M$ 7,5. The second one (Mortar II) was a mortar specifically designed for reparation uses, BIKAIN R3. The compressive strength and flexural strength of these mortars were experimentally determined in laboratory facilities following the standard EN 1015-11 (Committee AEN/CTN 83, 2007). From the data of the compressive strength tests, the Young's modulus was estimated. It has to be noticed that experimentally obtained values of the Young's modulus are lower than the commonly presented in other researches, maybe due to the testing procedure associated with the compressive strength test. Nevertheless, the masonry properties and the corresponding analytical results presented later on (see section 4) seem to support the validity of these data. The main properties of mortars are summarised in Table 1.

Two commercial epoxy resins, which were designed for the application of FRP laminates, were employed as joint materials to study the influence of casting stiffer joints with greater bonding properties than the cement mortar ones. The first epoxy resin (Resin I) was a primer, intended to assure the penetration into the pores of the bricks and usually applied with thin layers ( $<1 \mathrm{~mm}$ thick). This was distributed by BASF under the product name MasterBrace P3500. The second epoxy resin (Resin II) was an adhesive commonly used to bond FRP laminates to masonry or concrete structures. This was distributed by BASF under the product name MasterBrace ADH 4000. The main mechanical properties of these epoxy resins are summarised in Table 2.

A synthetic rubber material was also studied as joint element. In this case, representing a flexible joint with no bonding with the bricks was the aim of this selection. In particular, the used material was an ethylene propylene diene monomer (M-class) rubber, whose main properties is a density value of $80 \mathrm{~kg} / \mathrm{m}^{3}$ and a thickness of $20 \mathrm{~mm}$. In addition, this material was tested in laboratory conditions to obtain the stress-strain curve (Figure 1) for the stress range corresponding to the later on described tests on non-conventional masonry samples. Figure 1 is used later on to estimate the Young's modulus of the rubber joint. It is presented to completely characterise this material and provide comprehensive information. 
Finally, expanded polystyrene (EPS) was also analysed as a joint material, which was characterised by the littlest stiffness among the considered alternatives. Like rubber, this material was tested in the same conditions than non-conventional masonry to characterise its stress-strain response. Figure 1 summarises the mechanical response. The main properties of the used EPS are its density $\left(15 \mathrm{~kg} / \mathrm{m}^{3}\right)$ and thickness $(18 \mathrm{~mm})$.

\subsection{SAMPLES PRODUCTION}

Three different procedures were followed to build the samples depending on the joint material. All samples were piles of 5 bricks. This geometric configuration has been used by other researchers (Brencich et al., 2008, 2002) because these specimens are littler than the ones usually proposed in codes, e.g. (Committee AEN/CTN 41, 1999). Thus, choosing the 5 piled bricks geometric definition is justified in order to easy the test procedure and this election is also supported by bibliographic references.

The samples made with bricks and mortar, Figure 2a, were produced according with the common brick layering practice. This means that the bricks were wet before using them, the mortars were mixed with water following the recommendations of the providers. The alignment and levelling of the bricks was check at each row. In addition, the thickness of the joints was fixed placing little wood pieces between the corners of consecutive bricks. These wood elements were removed and the corresponding space filled with mortar when the joint was still fresh assuring a complete contact area between mortar and bricks.

The non-conventional masonry samples with resin joints were moulded into wooden formworks. However, the primer resin (Resin I) was more fluid than the adhesive one (Resin II), so the procedure was slightly different. For Resin I the bricks were placed into the formwork leaving a constant gap between them corresponding to the joint thickness, see Figure 2d. Then, Resin I was poured into the free spaces and cured for a week in indoor ambient conditions before unmoulding the samples. For Resin II, the bricks were placed into the mould one by one, with a layer of resin set on the surface that was facing the previous brick. This layer of resin was thicker than the desired joint. Little wood pieces were used to fix the separation between bricks. Every brick was pressed against the previous one up to the flow of the excess of resin which assured the complete filling of the joint, see Figure 2c. In this case, the formwork was used to restrain the resin flow through three lateral surfaces of the joint, forcing it to the upper side where the excessive material was removed.

Finally, bricks and joint layers, which were cut to fit the dimensions of bricks (270x125 $\mathrm{mm}^{2}$ ), were directly piled to produce the samples with dry joints, Figure $2 \mathrm{~b}$. These were built in the testing position to determine the modulus of linear elasticity.

Table 3 summarises the produced batches of samples and the corresponding joint material as well as it thickness. Six samples for every lot were produced and tested. The first sample of each lot was used to determine the compressive strength of the corresponding typology of masonry. This value was used to define the deformability tests performed on the five resting samples of the lot to obtain the Young's modulus. The compressive strength was also tested for these samples after finishing the non-destructive deformability test. Thus, a total of 60 samples were produced and 110 tests were carried out. 


\subsection{MODULUS OF LINEAR DEFORMATION}

First of all, it has to be mentioned that this procedure is based on the guidelines of the code (Committee AEN/CTN 41, 1999), although this standard procedure was adapted to the littler dimensions of the samples. In addition, the bottom and top surfaces of the specimens were not prepared with a mortar layer, as mentioned in the code, but a piece of carton. This option has proved suitable for the reported tests according with the obtained results and it was easier to execute than the code proposed preparation.

Five repetitions of the test to determine the modulus of linear deformation were carried out for each type of sample. All tests employed an oleo hydraulic actuator of $500 \mathrm{kN}$ range.

A detail of the test setup used to obtain the modulus of linear deformation can be observed in Figure 3. The samples were tested between two layers of carton, which were cut to the same area than bricks, to homogenise the contact between the bricks and the two symmetric thin steel plates used to distribute the load. The bottom steel plate was directly supported on a structural steel beam whereas the upper steel plate was loaded through a rigid bigger plate whose lateral displacements were partially restrained by the vertical bars which were used as guides of this last steel plate. Finally, an oleo hydraulic actuator applied a controlled force with a semi-circular steel tool to avoid the transmission of bending moment to the sample.

The testing procedure consisted in mounting the sample in the testing position, placing it on a carton base and these two elements on a thin steel plate. Then, two potentiometric displacement sensors with a resolution of $0.01 \mathrm{~mm}$ were installed on each lateral surface of the sample. In total, 4 displacement sensors were installed in each sample. These were screwed to a steel element, which was bonded with cyanoacrylate to the second brick of the pile. The free end of the sensor was placed in contact with an "L" stainless steel element bonded to the upper brick with cyanoacrylate. The initial distance between the two bonding points, $l_{0}$, was constant and equal for all sensors of the same sample batch (see Table 3 ). Thus, every sensor provided a measurement of the average strain between the two bonding points.

Once the sensors were installed, a carton layer, first, and a thin steel plate, after, were placed on the top of the sample. Then, this group was aligned with the actuator, and the acquisition of data began. The thicker steel plate was moved down guided by the vertical steel bars until getting in contact with the sample. The weight of this steel plate was considered the first load applied to the specimen. Finally, the actuator was used to apply a controlled force in three loading-unloading cycles: see Table 4 . In this table, the loading and unloading rate are presented. In addition, the time that the compressive force was kept constant after each loading process is summarised. It has to be noticed that no unloading process was considered for mortar joint specimens. This modification from the general testing process was made because no significant information was read during the unloading process of the other tests. The used potentiometers had no springs so they work only in compression (shortening) if they are placed in simple contact with the tested specimen. In addition, it has to be mentioned that the applied load for the specimens of the lot R1_5 (see Table 4) was limited for the capacity of the used actuator. For all other cases the maximum load reached during the test of the linear deformability corresponded to $50 \%$ of the compressive load-bearing capacity 
according with the compressive strength test carried out for one sample of each lot to set the parameters of the deformability test.

\subsection{COMPRESSIVE STRENGTH}

A destructive compressive strength test was performed on all samples except one of the lot R2_12, which failed in compression during the deformability test. Thus, 60 values of the compressive strength, six for each typology of joint, were determined.

This test consisted in placing the masonry sample in an oleo hydraulic press of $1 \mathrm{MN}$ range. No displacement sensors were installed and only the applied force was continuously recorded during the test execution. The loading rate was $10 \mathrm{kN} / \mathrm{s}$ for all specimens and the carton piece used in the previous deformation test was used to uniform the contact between the steel plates of the press and the bricks. The specimens tested to define the deformability experiments also used carton pieces to uniform the sample-press contact. The test setup can be observed in Figure 4.

\section{RESULTS}

\subsection{MODULUS OF LINEAR DEFORMATION}

Following the guidelines of the code (Committee AEN/CTN 41, 1999), the slope of the straight line which connected the origin of coordinates with the point corresponding to $1 / 3$ of the compressive resistance of the sample in the strain-stress plot was set to be the measurement of the modulus of linear deformation, $E$. This was calculated for every tested specimen and the average results are summarised in Table 5 for every series.

For the bonded joints, mortars and resins, the modulus of linear deformation ranged from $1000 \mathrm{MPa}$ to $16200 \mathrm{MPa}$, whereas the flexibility of the rubber and EPS is reflected in the far lower values of the modulus of linear deformation, which ranged from 8.5 to $17 \mathrm{MPa}$ in these cases. The scattering of the results is measured with the coefficient of variation, presented in brackets in Table 5. This is higher for the specimens with bonded joints than for the ones with dry joints.

\subsection{COMPRESSIVE STRENGTH}

The compressive strength, $f_{c}$, is the ratio of the maximum resisted force out of the area of the section perpendicular to the loading direction. This value was calculated for every sample and the average result for each series is summarised in Table 5. The compressive strength ranged from 7.4MPa to 31.3MPa depending on the considered joint. The scattering of the results is lower than for the modulus of linear deformation according with the coefficients of variation presented in Table 5.

\subsection{RATIO OF THE MODULUS OF LINEAR DEFORMATION OUT OF THE COMPRESSIVE STRENGTH}

Additionally, the ratio $E / f_{c}$ was calculated for every sample and averaged for each series to be presented in Table 5. This ratio is commonly used to characterise masonry and it is usually reported in literature.

For the specimens with bonded joints this ratio ranged from 109 to 808 . The influence of the material used in the joint was noticeable and analysed later on in the following section. Looking at the dry joint cases, this ratio was below 1 for EPS specimens and around 2.3 for samples with rubber joint. 


\section{COMPARISON AND DISCUSSION}

The average results presented in section 3 are compared to assess the influence of the studied variables. However, it has to be highlighted that the results of the modulus of linear deformation show significant scattering, which has to be considered when analysing them.

\subsection{INFLUENCE OF JOINT THICKNESS}

It is possible to analyse the influence of the joint thickness by comparing the specimens with the same joint material among them. According with the obtained evidences (see Table 5), increasing the joint thickness of the specimens with bonded joints contributes to reduce the compressive strength of the resulting masonry. The slight decrease of the compressive strength is observed for all cases with bonded joints and ranges from $1.7 \%$ for the M2 cases to $4.6 \%$ for $\mathrm{R} 1$ cases. This observation is typically justified by the lower compressive strength of the mortar joints in comparison with bricks and their higher relative amount in the specimens. However, this statement is not suitable for the cases with resin joints. In these cases, increasing the resin thickness over the maximum recommended one may justify a worse curing process and the corresponding decrease of the compressive strength of these joint materials, which might be related to an overall reduction of the compressive strength.

In addition, increasing the joint thickness of the specimens with bonded joints contributes to reduce the scattering of the compressive strength. This effect may be due to the better stress distribution of thicker joints, which avoided punctual stress concentrators usually associated with initial cracking processes. This behaviour was observed for all cases except for R2 samples, whose manual manufacture process and the troubles encountered at assuring the complete filling of the thicker joints would justify this anomalous response.

Regarding the modulus of linear deformation, it is observed that increasing the joint thickness of the specimens with the most flexible mortar, M1, or the most flexible resin, R1, contributes to reduce their modulus of linear deformation. This tendency is reversed for the cases with the stiffest mortar, M2, and resin, R2. Thus, modifying the stiffness of the joint material directly affects the stiffness of the resulting masonry in the same direction. It is also observed when comparing the modulus of linear deformability of the specimens with EPS or rubber (more flexible ones) to the samples with mortar of resins (stiffer ones).

Similarly to the compressive strength, increasing the joint thickness contributes to uniform the stress distribution avoiding punctual effects, which brings more repeatable results of the modulus of linear deformation and a lower coefficient of variation. This tendency is observed for all bonded cases.

Finally, modifying the thickness of the tested bonded joints causes the same tendency on the $E / f_{c}$ ratio than on the modulus of linear deformation analysed before. It is due to the greatest variation of $E$ in comparison with the slight change of $f_{c}$ when altering the thickness of the joint.

Thus, increasing the thickness of the stiffest bonded joints contributes to homogenise their structural response and causes an increase of the modulus of linear deformation of the resulting masonry. In this case, the slight associated reduction of the compressive strength might not justify using thinner joints. In contrast, if the joints are made of a flexible material, reducing their thickness may be interesting to obtain a stiffer compound material.

\subsection{INFLUENCE OF JOINT STIFFNESS}

Analysing the experimental results it can be noticed that the modulus of linear deformation of the masonry is influenced by the stiffness of the material used in the joint. In fact, the order of 
the masonry samples listed by their modulus of linear deformation coincides with the order of the modulus of linear deformation of the corresponding joints.

However, this influence of the stiffness of the joint material is not analogous on the compressive strength of the masonry specimens. Nevertheless, analysing only the cases with bonded joints the same trend than for the modulus of linear deformation is observed. Hence, the samples with more flexible joints show littler compressive strength. But there is an exception: the case of the Resin II (R2) did not follow this rule, maybe because of the problems at assuring the complete penetration of resin in the joint space.

As a result of the two previous discussions, the stiffness of the joints influences the $E / f_{c}$ ratio. But, although the general trend shown in the modulus of linear deformation of masonry samples is maintained for $E / f_{c}$ ratio, the order of samples M2 and R1 is altered. It has to be noticed that the modulus of linear deformation of these two joint materials are close (716 MPa for M2 and 875 MPa for R1) and the different adherence with the bricks may explain this evidence (see section 4.4).

Regarding the influence of the stiffness of the joints on the scattering of the compressive strength of the resulting masonry, no clear tendency can be observed. However, it is noticed that the samples with the more flexible joints show littler scattering on their modulus of linear deformation than those with stiffer joints. This might be due to the larger displacements measured for the more flexible samples, which minimised the influence of the possible errors of the recorded measurements in the calculation of the modulus of linear deformation.

Finally, it may be said that the influence of the stiffness of the joint interacts with the influence of the adherence of the joint as explained later on in section 4.4. This fact could explain the higher strength of the specimens with EPS joints, which did not show great adherence in contraposition to the samples with rubber joints or mortar joints.

\subsection{INFLUENCE OF JOINT COMPRESSIVE STRENGTH}

Taking into account that the modulus of linear deformation of the joints and their compressive strength are related variables, the analysis of the influence of the joint compressive strength brought similar results than the discussion on the influence of the modulus of linear deformation of the joints carried on in the previous section.

Thus, increasing the compressive strength of the joints is related with an increase of the modulus of linear deformation of the resulting masonry samples, but this phenomena seems related with the greater Young's modulus of the joint materials that show major compressive strength as analysed in section 4.2.

Similarly, analysing the specimens with bonded joints it is observed that placing joint materials with greater compressive strength contributes to improve the compressive strength of the resulting masonry samples. However, the specimens manufactured with the Resin II, which is the one with higher compressive strength, shown less compressive strength than those produced with Resin I. This fact may be related with the difficulties encountered at assuring the complete filling of the gap between bricks with Resin II during the fabrication process.

As a natural result of the previous considerations, the ratio $E / f_{c}$ seems influenced by the compressive strength of the joints but the influence of the modulus of elastic deformation of these joints is more significant according with the presented evidences (see Table 5). 


\subsection{INFLUENCE OF ADHERENCE}

Finally, it is worth analysing the influence of the joint-brick adherence from a qualitative point of view. This analysis is performed between the two series with joint resins and between the two series with dry joints (rubber and EPS). The discussion is limited to these cases because it is known that Resin I has better adherence than Resin II because of their aimed purposes and because of the roughness of the rubber assured greater friction with bricks than the soft surface of EPS.

Focusing in the cases with resin joints it is observed that the littler adherence of Resin II may have caused the littler compressive strength of the corresponding masonry samples. In addition, it can be noticed that the samples produced with Resin I showed far littler scattering in the results for both compressive strength and modulus of linear deformation.

Regarding the dry joint series (rubber and EPS) the opposite response was observed. Hence, the samples with littler friction between joints and bricks presented a higher compressive strength because the lateral deformation of the joint due to Poisson effect introduced littler tensile stresses in the bricks which resisted more than for the cases with greater friction between rubber joints and bricks.

Thus, assuring the joint-brick adherence contributes to increase the compressive strength of the masonry when joint material shows greater compressive strength than bricks but it is counterproductive when placing a joint material that is more flexible than bricks.

\subsection{COMPARISON WITH LITERATURE DATA}

Data from the literature have been considered in order to extend the discussion. Nevertheless, there is little research in this area which provides comprehensive information to compare to. Among others, experimental campaigns carried out by Brencich et al. (Brencich et al., 2008; Brencich and Felice, 2009; Brencich and Gambarotta, 2005) and Oliveira (Oliveira, 2000) are considered because of the completeness of the information provided. The considered data is shown in Table 6.

The influence of the joint thickness and the mortar-brick adherence cannot be analysed because all included literature tests used the same joint thickness and different adherence cases were not analysed.

Regarding the influence of the joint stiffness, it can be noticed that the general trend observed in the current campaign was previously observed by other researchers. Thus, the Young's modulus of the masonry increases when the Young's modulus of the joint increases. However, the influence of the stiffness of the joint on the $E / f_{c}$ ratio is not that clear in the literature data than in the one obtained in the current research campaign.

Finally, the influence of the joint compressive strength on the mechanical properties of the resulting masonry is not clear from the literature data. However, the results of two campaigns ((Brencich and Felice, 2009) and (Oliveira, 2000)) support the tendency observed in the current research: increasing the compressive strength of the mortar is related with an increase of the compressive strength, Young's modulus and $E / f_{c}$ ratio of the masonry.

\subsection{COMPARISON WITH ANALYTICAL FORMULATIONS}

The experimentally determined compressive strength is compared (Figure 5) with the one calculated using the formulation (Eq. 1) proposed by (Brencich et al., 2008) for unbounded masonry elements: 


$$
\widetilde{f_{M}}=\frac{h_{b} \frac{f_{c}^{m}}{f_{t}^{m}} f_{t}^{b}+h_{m} f_{c}^{m}}{h_{b} \frac{f_{c}^{m}}{f_{t}^{m}} f_{t}^{b}+h_{m} f_{c}^{b}} f_{c}^{b}
$$

where $f_{c}^{m}, f_{t}^{m}, f_{c}^{b}$ and $f_{t}^{b}$ are the compressive strength of joint, the tensile strength of joint, the compressive strength of bricks and tensile strength of bricks respectively. $h_{\mathrm{m}}$ and $h_{b}$ are the thickness of joint and brick respectively.

In order to apply this formulation, the tensile strength of Resin II is assumed to be 20MPa (in the same range that Resin I), $0.2 \mathrm{MPa}$ for EPS and 25MPa for rubber. The compressive strength of EPS was set to $0.1 \mathrm{MPa}$ and it was estimated at $25 \mathrm{MPa}$ for rubber. All these fits general producer's information but it is not specifically tested for the materials used in the experimental campaign. Hence, the results have to be analysed carefully.

The comparison between the experimental results, the analytical calculations using (Eq. 1) and the analytical calculations using Eurocode-6 (presented below) shows (see Figure 5) that the formulation proposed by (Brencich et al., 2008) is specially suitable for predicting the compressive strength of the prisms which used M1 mortar and R1 resin. However, Eurocode6 is more precise at predicting the compressive strength of prisms made with M2 mortar and R2 resin. Hence, formulation in (Eq. 1) seems more suitable for those cases which used bonded joints made of materials with lower compressive strength and lower value of the Young's modulus. Thus, it would be recommendable to use this expression (Eq. 1) instead of Eurocode-6 (European Committee for Standardization, 1997) to assess historical masonry structures. Both analytical formulations overestimate the compressive strength of prisms with rubber joints and underestimate it for the prisms with EPS joints. This response seems to indicate that the estimated values of the compressive strength for these two materials based on producers data overestimated the compressive strength of rubber and underestimated it for EPS. Finally, it is noticed that formulation in (Eq. 1) always brings higher values of the compressive strength than Eurocode-6 formulation. Analysing the influence of the different variables in (Eq. 1), it is concluded that the general response of Eurocode-6 fits with the cases of thicker joints made of a material with higher tensile strength which bonded bricks with minor tensile strength. Thus, using Eurocode- 6 may not be suitable to calculate the compressive strength of masonry made of high tensile strength bricks bonded with thin joints of little tensile strength mortar.

In addition, the experimentally determined Young modulus is compared (Figure 6) with the one calculated using the formulation (Eq. 2) proposed by (Francis et al., 1971) based on the mixture theory and elasticity:

$$
\frac{1}{E_{M}}=\frac{\eta_{b}}{E_{b}}+\frac{\eta_{m}}{E_{m}}+2 \eta_{m} \eta_{b} \frac{v_{b} E_{m}-v_{m} E_{b}}{\eta_{m}\left(1-v_{b}\right) E_{m}+\eta_{b}\left(1-v_{m}\right) E_{b}}\left(\frac{v_{m}}{E_{m}^{2}}-\frac{v_{b}}{E_{b}^{2}}\right)
$$

where $E_{M}, E_{m}$ and $E_{b}$ are the Young modulus of masonry, joint and brick respectively. $v_{m}$ and $v_{b}$ are the Poisson's coefficient of joint and brick. $\eta_{b}=t_{b} /\left(t_{m}+t_{b}\right)$ and $\eta_{m}=t_{m} /\left(t_{m}+t_{b}\right)$, where $t_{m}$ and $t_{b}$ are the thickness of joint and brick. The Young modulus of the EPS joint is set to 3MPa according with the data in Figure 1 for the loading range corresponding to the deformability tests. Similarly, the Young modulus of rubber is set to 3.5MPa. 
The comparison between the analytical formulation (Eq. 2), Eurocode-6 (presented below) and the experimental results (see Figure 6) shows that (Eq. 2) is better for estimating the Young modulus of prisms made with non-stacked joints of a material with an extremely low value of the Young modulus. For the specimens with resin joints (the stiffest ones among the tested cases, and the ones with the more reliable value of the Young modulus of the joints), Eurocode-6 tends to overestimate the Young modulus whereas (Eq. 2) tends to underestimate it. This same tendency is observed for specimens which used M1 mortar, but for the M2 mortar cases both methodologies overestimated the Young modulus of the prisms. This behaviour seems to indicate that the Young's modulus of M2 mortar, which was experimentally determined, might have been overestimated. Similarly, the Young modulus of M1 mortar might have been underestimated if analysed in comparison with the results of (Eq. 2). Comparing the results from (Eq. 2) with the results from Eurocode-6 and taking into account the influence of the variables in (Eq. 2), it is noticed that Eurocode- 6 formulation implicitly assumes a high value of the Young modulus of the mortar used in masonry joints.

In addition, Eurocode-6 (European Committee for Standardization, 1997) formulation - (Eq. 3) and (Eq. 4)- is applied on data from literature because these analytical approach requires less information than the previously used formulations. This formulation is aimed to calculate the compressive strength $\left(f_{c}\right)$ and the Young's modulus $(E)$ of solid fired clay brickwork from the compressive strength values of its components ( $f_{b}$ compressive strength of bricks and $f_{m}$ compressive strength of mortar).

$$
\begin{gathered}
f_{c}=0.55 f_{b}^{0.7} f_{m}^{0.3} \\
E=1000 f_{c}
\end{gathered}
$$

The analytical results obtained by applying these formula are presented together with the experimental data and the corresponding relative errors in Table 7. Figure 7 and Figure 8 are included to compare the results.

Firstly, it is important to notice that Eurocode 6 always overestimates $E / f_{c}$ ratio for the masonry prisms with mortar joints. Data from experimental programs (the current one and the ones from the literature considered) shows that $E / f_{c}$ ratio is always below the threshold value of 400 , whereas Eurocode 6 proposes to use $E / f_{c}=1000$.

The formulation proposed in Eurocode 6 fits the best for the cases with the most competent resin joint (Resin II). It is, for the samples which used the resin with the highest compressive strength, the highest Young's modulus and relatively low adherence, which contributes to reduce the tensile stress on the bricks due to the lateral deformation of the joint.

According with Table 7 and Figure 7, Eurocode 6 predicts better the compressive strength of those samples which use stiffer joints for all considered cases. However, the analysis of the accuracy of this formulation at predicting the Young's modulus of cement mortar masonry brings contradictory results (see Figure 8). For the literature considered cases, Eurocode 6 predicts better the Young's modulus of those samples which used a mortar with low compressive strength. In contrast, the best accuracy at predicting the Young's modulus of the masonry samples with cement mortar joints of the current campaign is observed in those cases with the greatest compressive strength of the joint material. 
Thus, the evidences seem to indicate that the formulation proposed in Eurocode 6 is more suitable for masonry elements built with high stiffness mortar joints than the ones currently used in general practise. In fact, only the case R2_12 (resin with a compressive strength of 73 $\mathrm{MPa}$ and a Young modulus of $8700 \mathrm{MPa}$ ) seems to be correctly represented by the formulation in Eurocode 6.

\section{CONCLUSIONS}

The results of the performed tests allow to conclude that:

- Using carton pieces to uniform the specimen to loading system contact is a suitable solution because no local failures were observed during the tests. It is an easy, cheap and fast alternative to the mortar face turning.

- The compressive strength of masonry is slightly reduced when the thickness of joints is increased.

- The compressive strength of masonry is increased by guaranteeing the adherence with the joint material when this one shows greater compressive strength than bricks but a frictionless contact is preferable if the joint material is far more flexible than bricks.

- The scattering of the compressive strength and modulus of linear deformability of masonry are reduced when the thickness of joints is increased.

- Using more flexible bonded joint material reduces the compressive strength of the resulting masonry.

- The stiffness of the mortar joint is the most influent variable on the compressive strength and the Young modulus of the masonry.

- $E / f_{c}$ ratio, which is commonly used for design purposes, is more influenced by the modulus of linear deformability than by the compressive strength.

- $E / f_{c}$ ratio is overestimated by the formulation proposed in Eurocode 6.

- Eurocode-6 formulation is especially suitable to calculate the compressive strength of masonry made of little tensile strength bricks bonded with thick joints of high tensile strength mortar.

- Eurocode-6 formulation implicitly assumes a high value of the Young modulus of the mortar used in masonry joints.

Finally, it is worth noticing that the obtained results may set the base for developing alternative building procedures for masonry incorporating new joint materials depending on the aimed purposes, or even using dry joints reducing the water consumption in the production place.

\section{REFERENCES}

Bernat, E., Gil, L., Roca, P., Sandoval, C., 2013. Experimental and numerical analysis of bending-buckling mixed failure of brickwork walls. Constr. Build. Mater. 43, 1-13. doi:http://dx.doi.org/10.1016/j.conbuildmat.2013.01.025

Brencich, A., Corradi, C., Gambarotta, L., 2008. Eccentrically loaded brickwork: Theoretical and experimental results. Eng. Struct. 30, 3629-3643.

doi:10.1016/j.engstruct.2008.05.010

Brencich, A., Corradi, C., Gambarotta, L., Mantegazza, G., Sterpi, E., 2002. Compressive strength of solid clay brick masonry under eccentric loading, in: Proceedings British Masonry Society. pp. 37-46. 
Brencich, A., Felice, G. De, 2009. Brickwork under eccentric compression: Experimental results and macroscopic models. Constr. Build. Mater. 23, 1935-1946. doi:10.1016/j.conbuildmat.2008.09.004

Brencich, A., Gambarotta, L., 2005. Mechanical response of solid clay brickwork under eccentric loading. Part I: Unreinforced masonry. Mater. Struct. 38, 257-266. doi:10.1617/14134

Committee AEN/CTN 136, 2011. EN 771-1:2011. Specification for masonry units - Part 1: Clay masonry unit.

Committee AEN/CTN 41, 1999. UNE-EN 1052-1:1999. Métodos de ensayo para fábricas de albañilería. Parte 1: Determinación de la resistencia a compresión.

Committee AEN/CTN 41, 2002. UNE-EN 772-1:2002. Métodos de ensayo de piezas para fábrica de albañilería. Parte 1: Determinación de la resistencia a compresión.

Committee AEN/CTN 83, 2007. UNE-EN 1015-11:2000/A1:2007. Métodos de ensayo de los morteros para albañilería. Parte 11: Determinación de la resistencia a flexión y a compresión del mortero endurecido.

European Committee for Standardization, 1997. Eurocode 6: Design of masonry structures. Part 1-1: General rules for buildings. Rules for reinforced and unreinforced masonry., Versión en. ed. AENOR, Madrid.

Francis, A.J., Horman, C.B., Jerrems, L.E., 1971. The effect of joint thickness and other factors on the compressive strength of brickwork, in: Proc. 2nd I. B. MA. C. Kent.

Gobierno del Distrito Federal, 2004. Normas técnicas complementarias para diseño y ocnstrucción de estructuras de mampostería, in: Gaceta Oficial Del Distrito Federal. Mexico D.F:

Kirtschig, K., Anstötz, W., 1991. Buckling tests on masonry, in: Proceedings of the 9th International Brick/Block Masonry Conference. IBMAC, Berlin, pp. 202-209.

Knutsson, H., 1991. Vertical load bearing masonry - The danish approach. Mason. Int. 5, 2326.

Masonry Standards Joint Committee, 2005. Building Code Requirements for Masonry Structures. ACI 530-05.

Maurenbrecher, A.H.P., 1980. Effect of the test procedures on compressive strength of masonry prisms, in: 2nd Canadian Masonry Symposium. National Research Council Canada, Ottawa, pp. 119-132.

Maurenbrecher, A.H.P., 1983. Compressive Strength of eccentrally loaded masonry prisms, in: NRCC (Ed.), Third Canadian Masonry Symposium. National Research Council Canada, Edmonton.

Maurenbrecher, A.H.P., 1985. Axial Compression Tests on Masonry Walls and Prisms, in: Third North American Masonry Conference. National Research Council Canada, Arlington, Texas, p. 17.

Molins, C., 1996. Characterization of the mechanical behaviour of masonry, in: Roca, P. (Ed.), Structural Analysis of Historical Constructions. CIMNE, Barcelona.

Oliveira, D., 2000. Mechanical characterization of stone and brick masonry, report 00-Dec/E4, Universidade do Minho, Departamento de Engenharia Civil, Guimarães, Portugal. 
Guimarães, Portugal.

Roberts, T., Hughes, T., Dandamudi, V., Bell, B., 2006. Quasi-static and high cycle fatigue strength of brick masonry. Constr. Build. Mater. 20, 603-614.

doi:10.1016/j.conbuildmat.2005.02.013

Sandoval, C., Roca, P., Bernat, E., Gil, L., 2011. Testing and numerical modelling of buckling failure of masonry walls. Constr. Build. Mater. 25, 4394-4402. doi:10.1016/j.conbuildmat.2011.01.007

Watstein, D., Allen, M.H., 1970. Structural performance of clay masonry assemblages built with high-bond organic-modified mortars, in: Second International Brick Masonry Conference. Structural Clay Products Institute, pp. 99-112. 


\section{TABLES}

Table 1. Mechanical properties of bricks and mortars. Results from experimental tests. Coefficient of variation in brackets

\begin{tabular}{|c|c|c|c|}
\hline Material & $\begin{array}{c}\text { Compressive strength } \\
(\mathbf{M P a})\end{array}$ & Flexural strength (MPa) & Young's Modulus (MPa) \\
\hline Brick & $27.93(0.19)$ & $5.99(0.48)$ & $12149(0.14)$ \\
\hline Mortar I & $3.55(0.10)$ & $1.46(0.10)$ & $131(0.39)$ \\
\hline Mortar II & $15.63(0.10)$ & $4.06(0.10)$ & $716(0.17)$ \\
\hline
\end{tabular}

Table 2. Mechanical properties of resins provided by producers.

\begin{tabular}{|c|c|c|}
\hline Property & Resin I & Resin II \\
\hline Density $\left(\mathrm{g} / \mathrm{cm}^{3}\right)$ & 1.05 & 1.70 \\
\hline Tensile strength $(\mathrm{MPa})$ & 22.9 & $*$ \\
\hline Compressive strength $(\mathrm{MPa})$ & 28.3 & 73 \\
\hline Young's modulus $(\mathrm{MPa})$ & 875 & 8700 \\
\hline Adherence with concrete $(\mathrm{MPa})$ & 7.0 & 5.4 \\
\hline
\end{tabular}

* Data not provided by the producer

Table 3. Sample lots and their corresponding joint definition and measurement length for deformation tests.

\begin{tabular}{|c|c|c|c|}
\hline Sample batch & Joint material & Joint thickness $(\mathbf{m m})$ & $\mathbf{I}_{\mathbf{0}}(\mathbf{m m})$ \\
\hline M1_10 & Mortar I & 10 & 160 \\
\hline M1_20 & Mortar I & 20 & 170 \\
\hline M2_5 & Mortar II & 5 & 250 \\
\hline M2_10 & Mortar II & 10 & 160 \\
\hline R1_5 & Resin I & 5 & 190 \\
\hline R1_10 & Resin I & 10 & 200 \\
\hline R2_8 & Resin II & 8 & 180 \\
\hline R2_12 & Resin II & 12 & 180 \\
\hline EPS & EPS & 18 & 225 \\
\hline RUB & Rubber & 20 & 180 \\
\hline
\end{tabular}


Table 4. Loading pattern for the deformability tests

\begin{tabular}{|c|c|c|c|c|c|c|}
\hline \multirow{2}{*}{$\begin{array}{c}\text { Sample } \\
\text { batch }\end{array}$} & \multirow{2}{*}{$\begin{array}{l}\text { Loading } \\
\text { rate } \\
\text { (kN/min) }\end{array}$} & \multirow{2}{*}{$\begin{array}{c}\text { Unloading rate } \\
\text { (kN/min) }\end{array}$} & \multirow{2}{*}{$\begin{array}{c}\text { Time constant } \\
\text { force (min) }\end{array}$} & & $\begin{array}{c}\text { Maximum } \\
\text { loading force } \\
(\mathrm{kN})\end{array}$ & \\
\hline & & & & $\begin{array}{c}1^{\text {st }} \\
\text { cycle }\end{array}$ & $2^{\text {nd }}$ cycle & $\begin{array}{c}3^{\text {rd }} \\
\text { cycle }\end{array}$ \\
\hline M1_10 & 29.5 & --- & 2 & 73.8 & 147.6 & 221.4 \\
\hline M1_20 & 17.3 & --- & 2 & 43.3 & 86.7 & 130.0 \\
\hline M2_5 & 45.1 & --- & 2 & 112.7 & 225.3 & 338.0 \\
\hline M2_10 & 43.1 & --- & 2 & 109.0 & 218.0 & 327.0 \\
\hline R1_5 & 100.0 & 300.0 & 2 & 150.0 & 300.0 & 450.0 \\
\hline R1_10 & 83.3 & 250.0 & 2 & 125.0 & 250.0 & 375.0 \\
\hline R2_8 & 78.7 & 236.1 & 2 & 118.1 & 236.1 & 354.2 \\
\hline R2_12 & 91.5 & 274.6 & 2 & 137.3 & 274.6 & 411.9 \\
\hline EPS & 22.2 & 66.6 & 2 & 33.3 & 66.7 & 100.0 \\
\hline RUB & 20.9 & 62.6 & 2 & 31.3 & 62.6 & 93.9 \\
\hline
\end{tabular}

Table 5. Results of the compressive strength, $f_{c}$, modulus of linear deformation, $E$, and the ratio $E / f_{c}$. Coefficient of variation in brackets.

\begin{tabular}{|c|c|c|c|}
\hline Sample batch & $\boldsymbol{f c}(\mathbf{M P a})$ & $\boldsymbol{E}(\mathbf{M P a})$ & $\boldsymbol{E} / \boldsymbol{f c}$ \\
\hline M1_10 & $9.5(0.33)$ & $1522(0.86)$ & 160 \\
\hline M1_20 & $9.3(0.17)$ & $1011(0.64)$ & 109 \\
\hline M2_5 & $17.3(0.25)$ & $4685(0.62)$ & 272 \\
\hline M2_10 & $17.0(0.08)$ & $6415(0.34)$ & 377 \\
\hline R1_5 & $31.3(0.16)$ & $8927(0.78)$ & 285 \\
\hline R1_10 & $29.9(0.09)$ & $7960(0.62)$ & 266 \\
\hline R2_8 & $20.7(0.23)$ & $14738(1.22)$ & 711 \\
\hline R2_12 & $20.0(0.42)$ & $16200(0.64)$ & 808 \\
\hline EPS & $11.1(0.36)$ & $8.5(0.05)$ & 0.77 \\
\hline RUB & $7.4(0.16)$ & $17.0(0.13)$ & 2.31 \\
\hline
\end{tabular}


Table 6. Experimental data from concentric compressive tests on solid brick masonry samples. Joint thickness $=10 \mathrm{~mm}$.

\begin{tabular}{|c|c|c|c|c|c|c|c|c|}
\hline \multirow[b]{2}{*}{$\begin{array}{c}\text { Sample } \\
\text { batch }\end{array}$} & \multirow[b]{2}{*}{ Source } & \multicolumn{2}{|c|}{ Mortar } & \multicolumn{2}{|c|}{ Brick } & \multicolumn{3}{|c|}{ Masonry } \\
\hline & & $\begin{array}{c}f c \\
(M P a)\end{array}$ & $\begin{array}{c}E \\
(M P a)\end{array}$ & $\begin{array}{c}f c \\
(M P a)\end{array}$ & $\begin{array}{c}E \\
(M P a)\end{array}$ & $\begin{array}{c}f c \\
(M P a)\end{array}$ & $\begin{array}{c}E \\
(M P a)\end{array}$ & $E / f c$ \\
\hline A & $\begin{array}{l}\text { (Brencich and } \\
\text { Gambarotta, } \\
\text { 2005) }\end{array}$ & 14.7 & 335 & 19.9 & 2400 & 9.9 & 1260 & 127 \\
\hline B & $\begin{array}{l}\text { (Brencich and } \\
\text { Gambarotta, } \\
\text { 2005) }\end{array}$ & 11.4 & 335 & 19.9 & 2400 & 13.5 & 1620 & 120 \\
\hline $\mathrm{C}$ & $\begin{array}{c}\text { (Brencich et al., } \\
\text { 2008) }\end{array}$ & 9.2 & 1545 & 13.8 & 1530 & 13.5 & 2035 & 151 \\
\hline $\mathrm{D}$ & $\begin{array}{c}\text { (Brencich et al., } \\
\text { 2008) }\end{array}$ & 7.0 & 1365 & 13.8 & 1530 & 13.2 & 2085 & 158 \\
\hline $\mathrm{E}$ & $\begin{array}{l}\text { (Brencich and } \\
\text { Felice, 2009) }\end{array}$ & 13.1 & 1545 & 19.7 & 1530 & 13.5 & 1867 & 138 \\
\hline $\mathrm{F}$ & $\begin{array}{l}\text { (Brencich and } \\
\text { Felice, 2009) }\end{array}$ & 10.0 & 1365 & 19.7 & 1530 & 13.2 & 1700 & 129 \\
\hline G & $\begin{array}{l}\text { (Brencich and } \\
\text { Felice, 2009) }\end{array}$ & 2.3 & 480 & 30.5 & 3920 & 7.5 & 2313 & 308 \\
\hline $\mathrm{H}$ & (Oliveira, 2000) & 6.2 & 4190 & 56.8 & 12750 & 28.2 & 10700 & 379 \\
\hline I & (Oliveira, 2000) & 4.8 & 1570 & 56.8 & 12750 & 28.3 & 10500 & 371 \\
\hline
\end{tabular}

Table 7. Experimental and analytical (Eurocode 6) values of the compressive strength and Young's modulus.

\begin{tabular}{|c|c|c|c|c|c|c|}
\hline \multirow{2}{*}{ Sample batch } & \multicolumn{2}{|c|}{ Experimental } & \multicolumn{4}{c|}{ Eurocode 6 } \\
\cline { 2 - 7 } & $\boldsymbol{f}_{\boldsymbol{c}}(\mathbf{M P a})$ & $\boldsymbol{E}(\mathbf{M P a})$ & $\boldsymbol{f}_{\boldsymbol{c}}(\mathbf{M P a})$ & Error $\boldsymbol{f}_{\boldsymbol{c}}(\%)$ & $\boldsymbol{E}(\mathbf{M P a})$ & Error E (\%) \\
\hline M1_10 & 9.5 & 1522 & 8.3 & -12.6 & 8302 & 445.5 \\
\hline M1_20 & 9.3 & 1011 & 8.3 & -10.7 & 8302 & 721.2 \\
\hline M2_5 & 17.3 & 4685 & 12.9 & -25.5 & 12889 & 175.1 \\
\hline M2_10 & 17.0 & 6415 & 12.9 & -24.2 & 12889 & 100.9 \\
\hline R1_5 & 31.3 & 8927 & 15.4 & -50.8 & 15411 & 72.6 \\
\hline R1_10 & 29.9 & 7960 & 15.4 & -48.5 & 15411 & 93.6 \\
\hline R2_8 & 20.7 & 14738 & 20.5 & -1.1 & 20478 & 38.9 \\
\hline R2_12 & 20.0 & 16200 & 20.5 & 2.4 & 20478 & 26.4 \\
\hline A & 9.9 & 1260 & 10.0 & 1.0 & 9994 & 693.2 \\
\hline B & 13.5 & 1620 & 9.3 & -31.4 & 9260 & 471.6 \\
\hline C & 13.5 & 2035 & 6.7 & -50.2 & 6721 & 230.3 \\
\hline D & 13.2 & 2085 & 6.2 & -53.1 & 6192 & 197.0 \\
\hline E & 13.5 & 1867 & 9.6 & -29.0 & 9587 & 413.5 \\
\hline F & 13.2 & 1700 & 8.8 & -33.0 & 8841 & 420.0 \\
\hline G & 7.5 & 2313 & 7.7 & 3.0 & 7725 & 234.0 \\
\hline H & 28.2 & 10700 & 16.1 & -43.0 & 16074 & 50.2 \\
\hline I & 28.3 & 10500 & 14.9 & -47.4 & 14886 & 41.8 \\
\hline
\end{tabular}




\section{FIGURES}

Figure 1. Stress-strain compressive response of the rubber and EPS used as a joint.
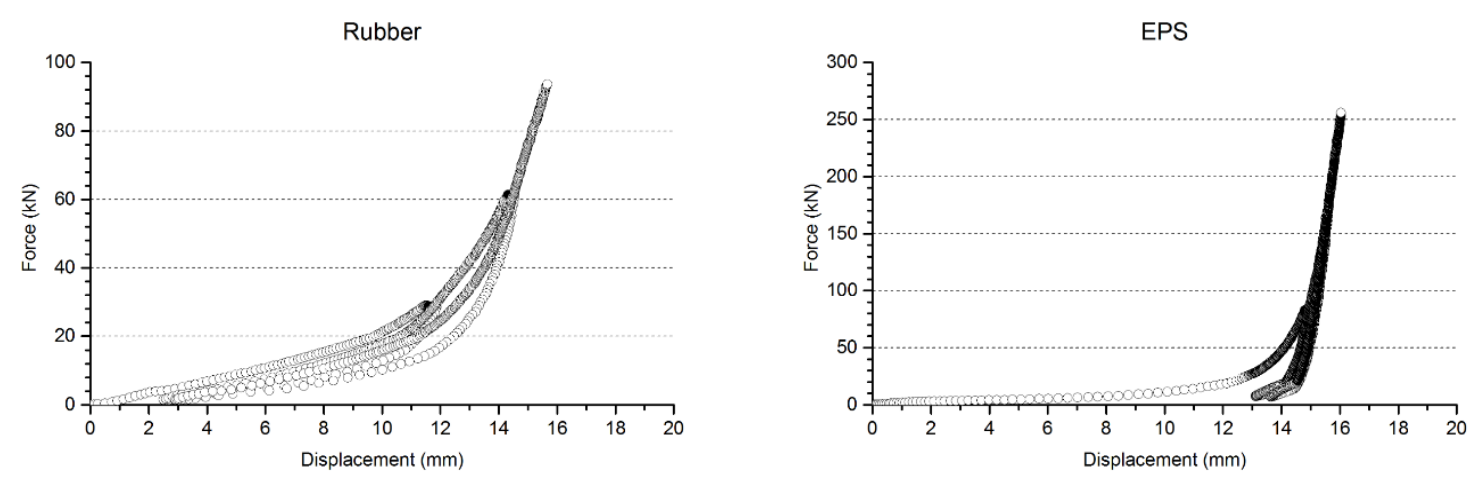

Figure 2. Samples production: a) Conventional samples with mortar joints, b) dry joint sample with EPS, c) moulding process for the Resin II, d) moulding process before pouring Resin I.

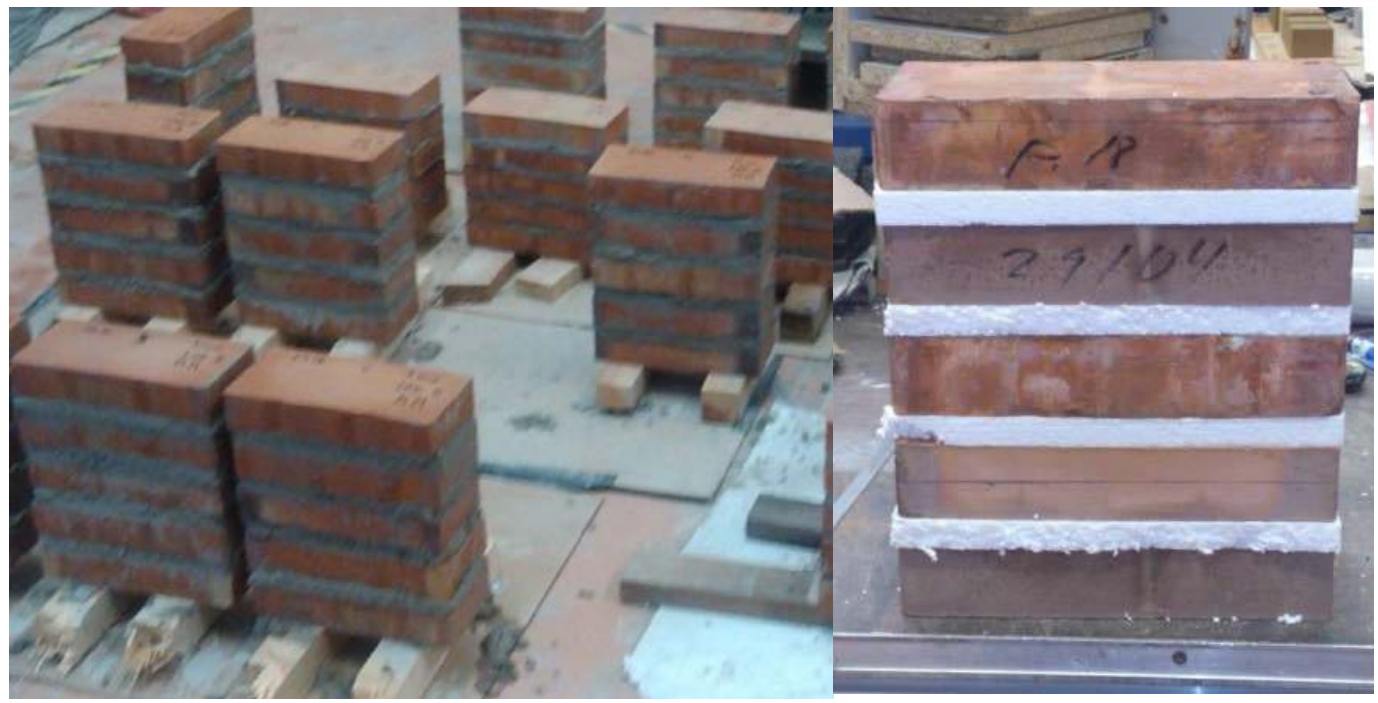

a)

b)

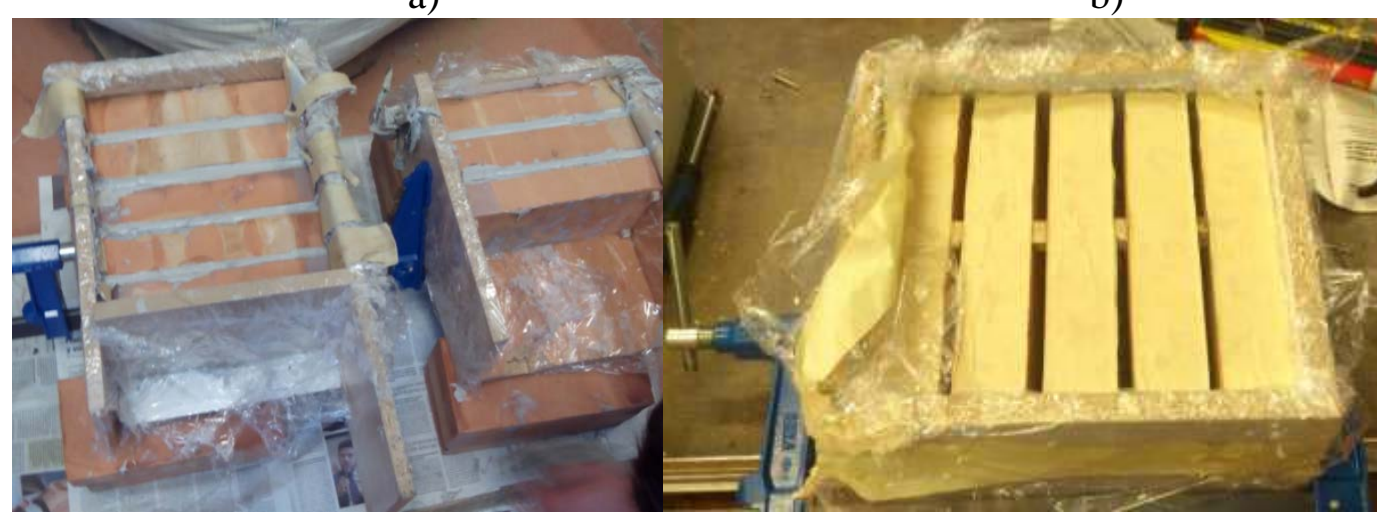

c)

d) 
Figure 3.Test setup for determining the modulus of linear deformation

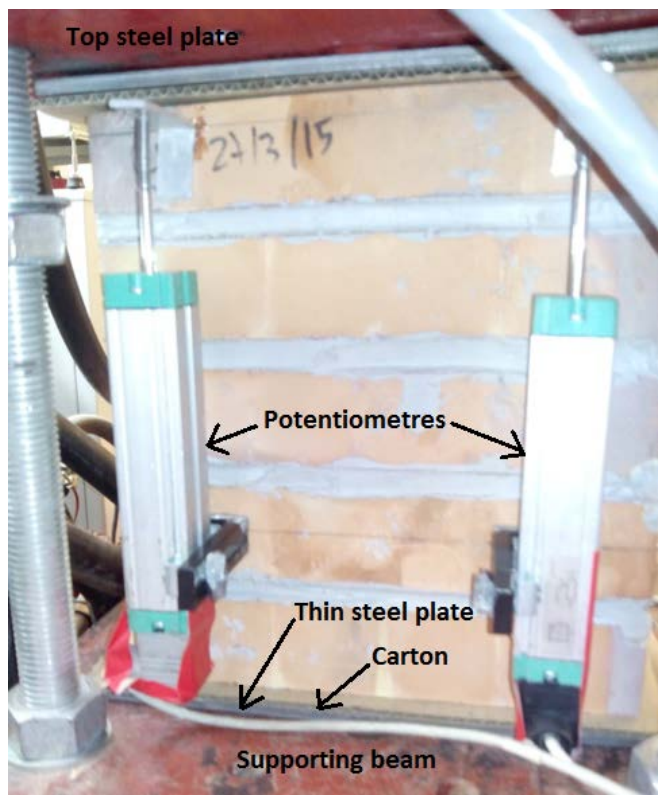

Figure 4. Third specimen of the lot R1_5 before (left) and after (right) the compressive strength test.
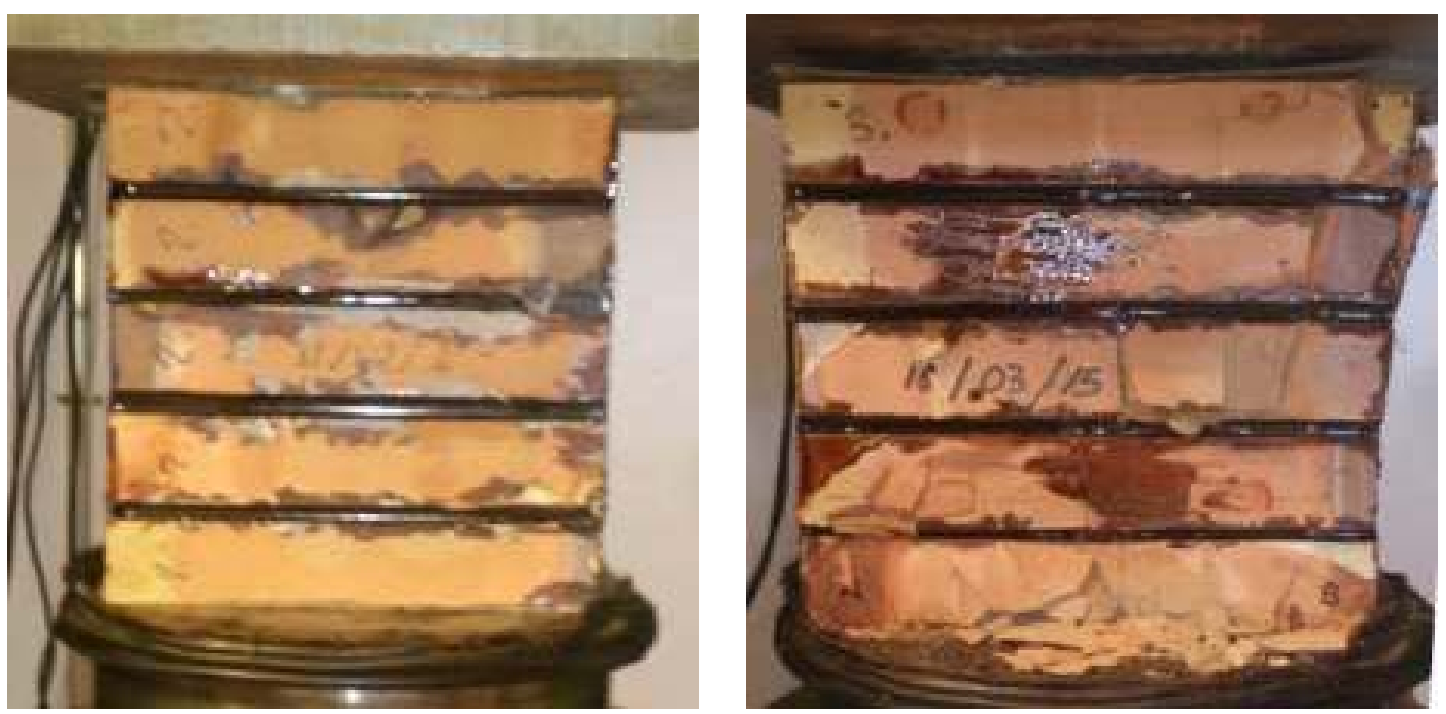
Figure 5. Brencich et al. (2008) vs. Eurocode-6 calculation of the compressive strength

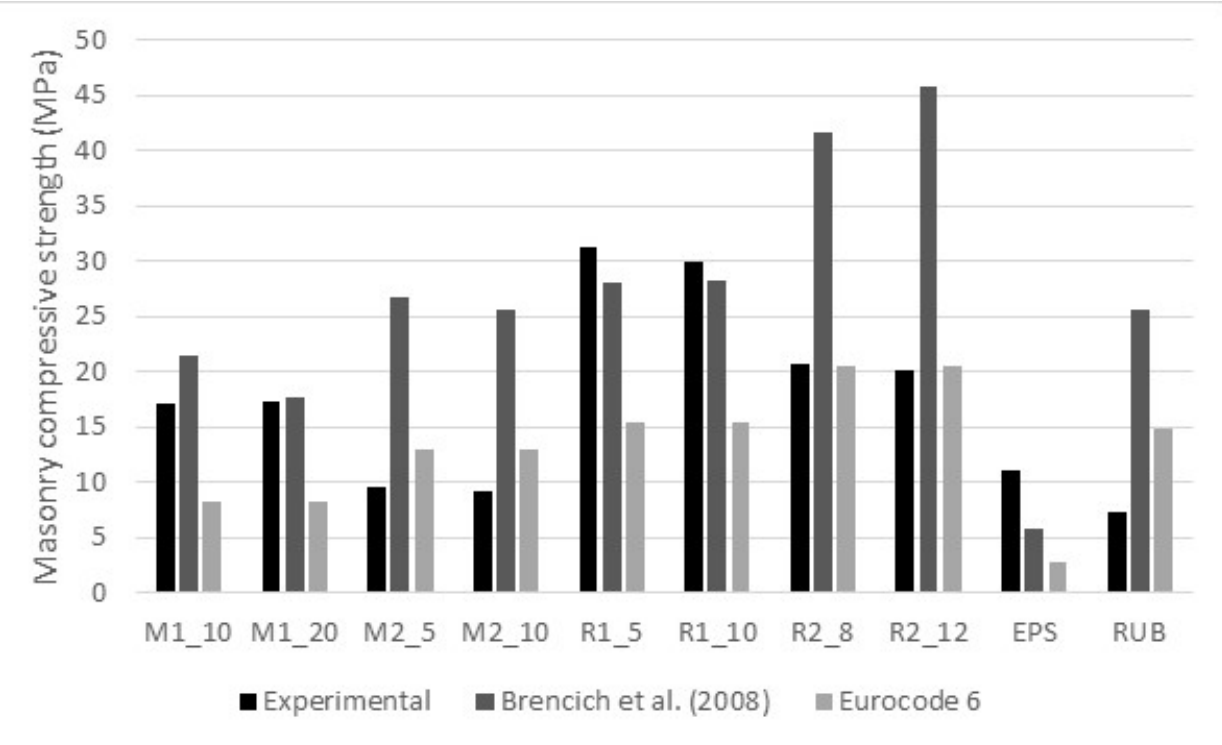

Figure 6. Francis et al. (1971) vs. Eurocode-6 calculation of the Young’s modulus

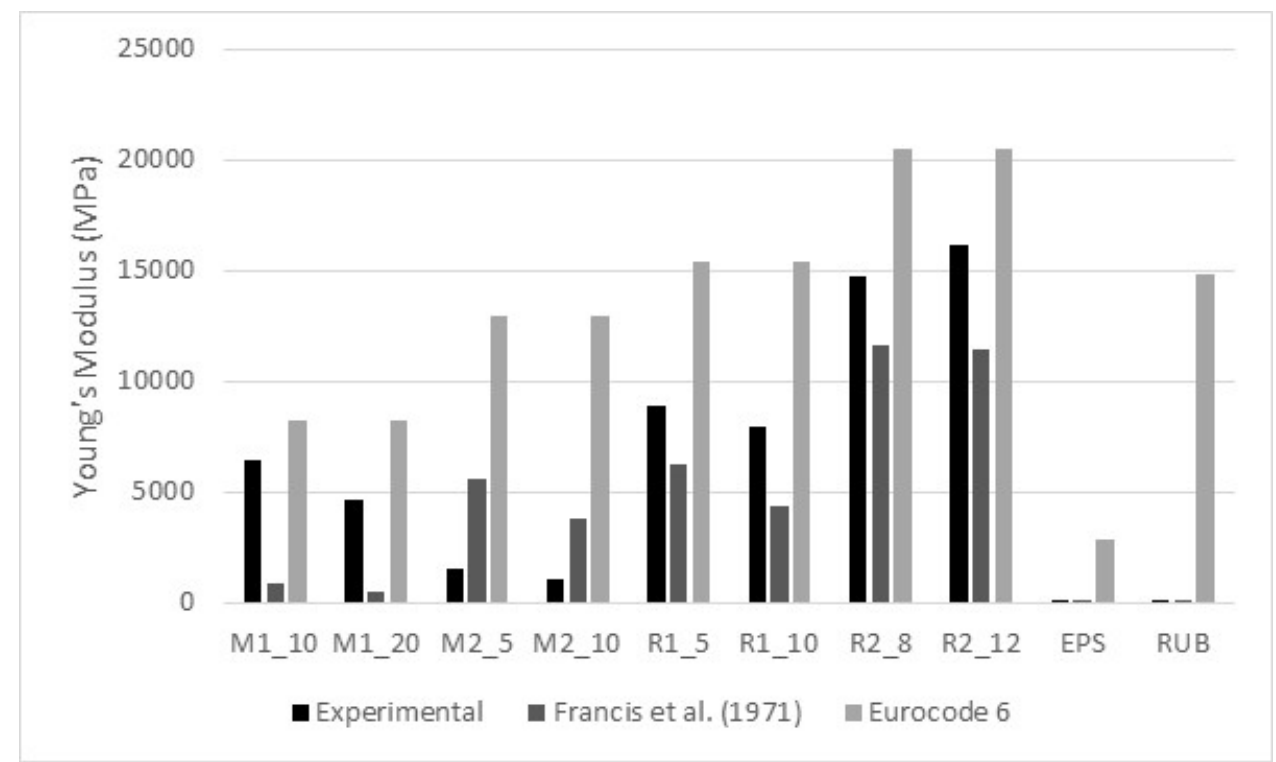


Figure 7. Experimental and EC-6 calculated compressive strength

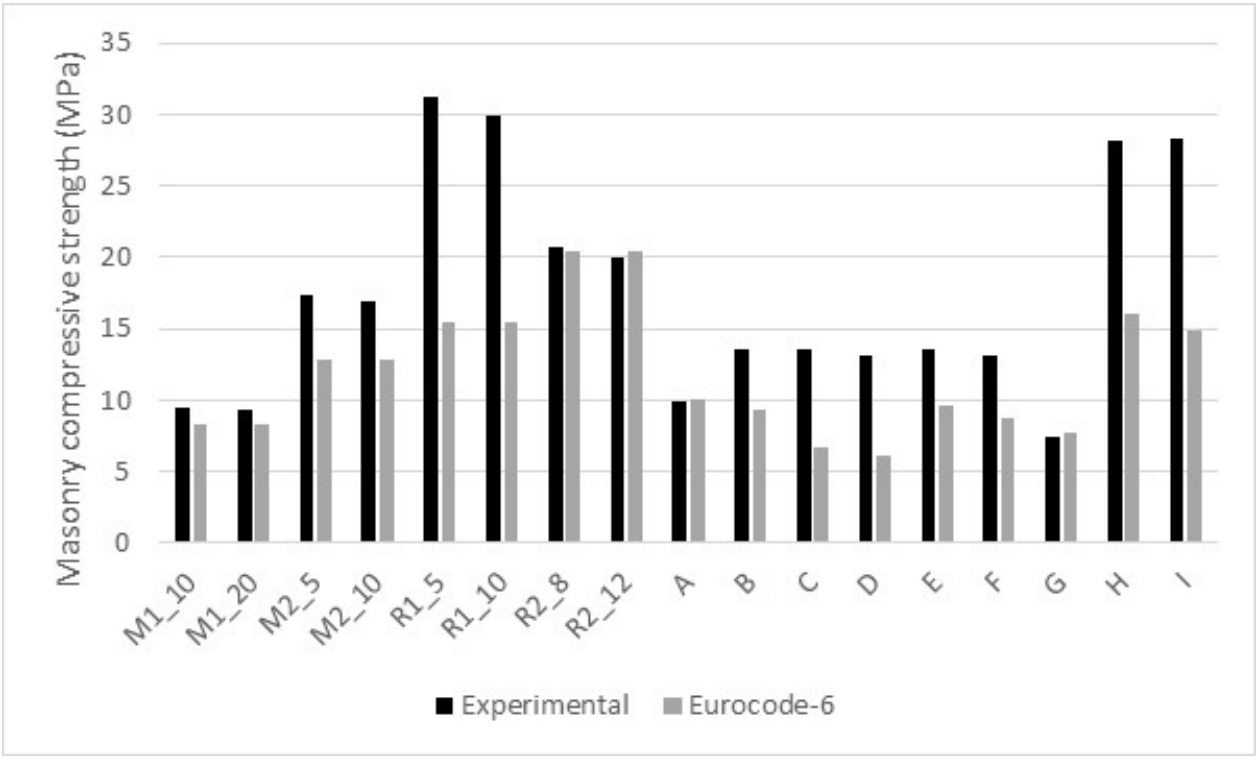

Figure 8. Experimental and EC-6 calculated Young modulus

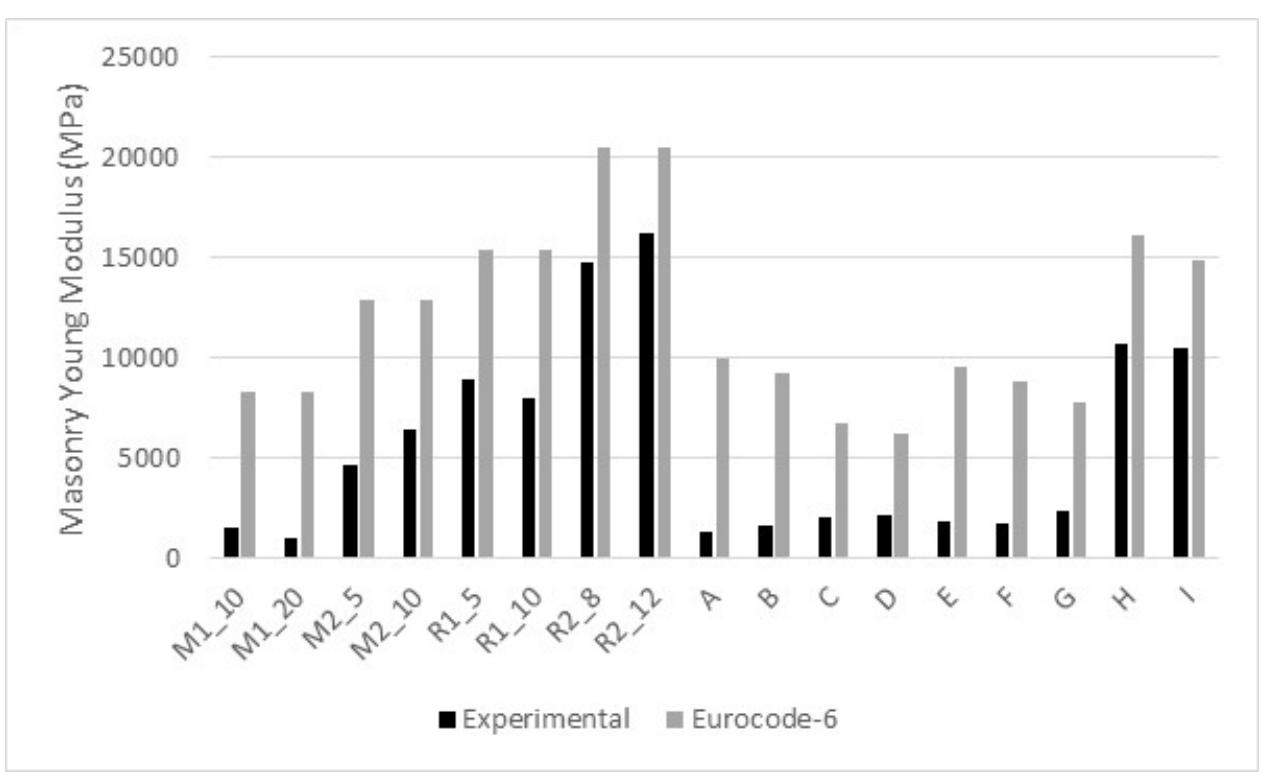

